SESSION IV

(Session commune avec la Commission Ovine et Caprine)

SÉLECTION POUR LA FERTILITÉ CHEZ LE MOUTON

\title{
Selection for fertility in sheep. Theoretical aspects
}

\author{
G. NITTER \\ Institut für Tierhaltung und Tierzüchtung der Universität Hohenheim, \\ Postfach 700562/470, D-7000 Stuttgart 70, B.R.D.
}

This paper discusses two aspects of selection for reproduction performance in sheep. The first is the economic relevance. It is demonstrated that the economic return from increasing litter size decreases rapidly with increasing average of the population. The economic importance of reducing the phenotypic variance is emphasized and problem of stabilizing selection are discussed.

In the second part the paper deals with the genetic complexity of reproductive traits being affected by direct, maternal, grandmaternal and paternal genetic components. It is shown that the various methods of heritability estimation differ considerably in what they really estimate. Furthermore, it is demonstrated how a population develops in different directions dependent on the information available for selection. Evidence for non-maternal genetic effects and for relationships between them is reviewed from the literature and discussed from a physiological point of view.

\section{Nature of the genetic control of ovulation rate and its relationship with litter size}

\author{
J.P. HANRAHAN and L.R. PIPER
}

The Agricultural Institute, Belclare, Tuam, Co. Galway, Ireland and C.S.I.R.O., Armidale, N.S.W. Australia

Fecundity differences among sheep breeds and responses to selection for increased litter size are all attributable to differences in ovulation rate. The heritability of ovulation rate is high in the Finn breed $(0.45 \pm .07)$ and has shown a corresponding response to selection. Significant heritability estimates have also been reported for Galway and Merino populations.

In the Booroola Merino the segregation of a major gene (effect $=3 \sigma$ ), with an additive effect on ovulation rate, has been demonstrated. The relationship between ovulation rate and litter size is curvilinear and it is proposed that genetic variation in litter size is due to genetic variation in ovulation rate. A model incorporating this proposition and embryo survival estimates (as a function of ovulation rate) permits genetic and phenotypic parameters for litter size to be expressed in terms of the corresponding parameters for ovulation rate. 